\title{
Turning a Cr-based heterogeneous ethylene polymerisation catalyst into a selective ethylene trimerisation catalyst
}

\author{
Cristina N. Nenu ${ }^{\mathrm{a}}$, Philippe Bodart ${ }^{\mathrm{b}}$, Bert M. Weckhuysen ${ }^{\mathrm{a}, *}$ \\ a Inorganic Chemistry and Catalysis, Department of Chemistry, Utrecht University, PO Box 80083, 3508 TB Utrecht, The Netherlands \\ ${ }^{\mathrm{b}}$ Total Petrochemicals Research, Zone Industrielle C, B-7181 Feluy, Belgium \\ Received 16 October 2006; accepted 26 December 2006 \\ Available online 5 January 2007
}

\begin{abstract}
A Phillips $\mathrm{Cr} / \mathrm{SiO}_{2}$ polymerisation catalyst was converted into an ethylene trimerisation catalyst after assembling new active sites on the silica surface in the presence of TAC (1,3,5-triphenylhexahydro 1,3,5-triazacyclohexane) as ligand and $\mathrm{CH}_{2} \mathrm{Cl}_{2}$ as solvent. The reaction conditions play a role in tuning the catalytic activity of this system. It is a true trimerisation catalyst at low ethylene pressures, while, at high pressures, the polymerisation activity becomes dominant. Moreover, at high ethylene pressures, polyethylene characterised by a high crystallinity degree is obtained. Instead, a highly branched heavy oligomer of ethylene characterised by a very narrow molecular weight distribution is obtained at 1 bar. 1-Hexene, formed as the main product in the ethylene trimerisation reaction at low pressures, is partially incorporated into this growing oligomer making redundant the use of a second comonomer feedstock and an expensive catalyst.
\end{abstract}

(c) 2007 Elsevier B.V. All rights reserved.

Keywords: Ethylene trimerisation; Ethylene polymerisation; Single-site heterogeneous catalysts; LLDPE; Phillips catalyst

\section{Introduction}

Considerable effort is made to develop chemical processes where copolymers of ethylene and 1-hexene are obtained. These copolymers, named linear low-density polyethylenes (LLDPE), have butyl short-chain branches grafted onto the carbon backbone. Currently, they are industrially obtained using a two-step process: production of 1-hexene by ethylene oligomerisation and subsequent use of 1-hexene in the production of LLDPE. A single-step process involves either the use of a bi-functional catalyst active in both processes or the use of a tandem catalytic system [5-8]. So far, no homogeneous catalysts are reported to be simultaneously active in both processes and, therefore, more attention is paid to heterogeneous systems, which present the advantage that different active sites can be created on a support surface. Because chromium may efficiently act in both processes, the idea of heterogenisation of a chromium trimerisation centre onto a support material is a logical step in the development of a novel trimerisation catalyst. Currently, the most important

\footnotetext{
* Corresponding author. Fax: +31 302531027.

E-mail address: b.m.weckhuysen@chem.uu.nl (B.M. Weckhuysen).
}

processes that use $\mathrm{Cr}$ catalysts for the production of 1-hexene are either the catalytic oligomerisation of ethylene that results in a wide range of olefins or the selective trimerisation of ethylene [9]. Phillips ethylene trimerisation technology can give a high yield of 1-hexene with a purity of above $90 \%$. In fact, the Phillips trimerisation technology is the sole ethylene trimerisation-based process, which is industrially applied. It uses mild process conditions $\left(115^{\circ} \mathrm{C}\right.$ and ambient pressure) and produces $45-50 \mathrm{~kg} / \mathrm{cm}^{3}$ trimer. Small amounts of 1-octene and 1-decene are also formed, while solid product formation is negligible.

When reading on other Cr-based homogeneous ethylene trimerisation systems, one may notice that polymer by-products are always formed and, often, in considerable amounts. Table 1 presents a short literature survey of the main by-products obtained on the most important Cr-based homogeneous trimerisation catalysts. This dual activity of $\mathrm{Cr}$ might be exploited in obtaining a single catalytic system active simultaneously in both processes, polymerisation and trimerisation of ethylene. The choice of the coordinating ligands and of their substituents plays the key role because they can modulate the catalytic activity of the system. Such effects are also reported for homogeneous Cr-based ethylene trimerisation systems. An interesting example is the intramolecular coordination of aromatic groups to 
Table 1

Literature survey of the different homogeneous Cr-based trimerisation catalysts and their most important by-products

\begin{tabular}{|c|c|c|c|c|c|c|c|}
\hline Catalytic system & Co-catalyst & $1-\mathrm{C}_{4}$ & $\mathrm{C}_{6}$ fraction & $1-\mathrm{C}_{8}$ & $1-\mathrm{C}_{10}$ & $\mathrm{PE}$ & Reference \\
\hline $\mathrm{Cr}^{\mathrm{III}}$-2-ethylhexanoate & $\mathrm{Al}(\mathrm{iBu})_{3}$ & + & + & + & + & + & {$[1]$} \\
\hline Diphosphine Cr complexes & MMAO & + & + & + & + & - & {$[2]$} \\
\hline Aminosubstituted cyclopentadienyl $\mathrm{Cr}$ derivatives & MAO & \multicolumn{4}{|c|}{ Not reported } & + & [3] \\
\hline $\mathrm{Cr}\left[\mathrm{N}\left(\mathrm{SiMe}_{3}\right)_{2}\right]_{3}$ & $i$-BuAO & + & + & + & + & + & [4] \\
\hline
\end{tabular}

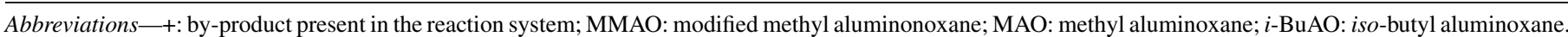

half-sandwich Ti catalyst, which is able to switch the catalyst selectivity from ethylene polymerisation towards ethylene trimerisation. This system is comparable with the best currently available Cr-based catalyst for ethylene trimerisation and it was reported for the first time by the group of Hessen and coworkers $[10,11]$.

$\mathrm{Cp}$ Cr-based catalysts were reported as very active ethylene polymerisation catalysts $[12,13]$. Recently, it was shown that, when bulky aromatic substituents are part of the $\mathrm{Cp}$ ring, the polymerisation activity is inhibited and the trimerisation activity of the catalyst develops $[3,14,15]$.

Another group of polymerisation-trimerisation catalysts is based on TAC (1,3,5-triazacyclohexane) ligands. Substituents of the TAC ring can modulate the catalytic activity of $\mathrm{Cr}-\mathrm{TAC}$ complexes. Hydrogen substituents give the most active TAC-Crbased trimerisation catalysts, while bulky substituents of the TAC ring inhibit the trimerisation activity at the expense of oligomerisation or polymerisation activity [16]. Ligands with intermediate steric effects will form bi-functional catalysts, active in both processes. In this case, reaction conditions can further influence and modulate the catalytic activity. Finally, highly branched substituents develop TAC-Cr-based catalysts active in the isomerisation of alpha-olefins [17].

Diimine ligands with different transition metals form active homogeneous complexes in the polymerisation of ethylene [18]. Ni-based diimine catalyst can produce polyethylene with shortchain branches through a chain-walking mechanism [5,19-24]. In 1997, Sumitomo Chemical Company has patented a process of ethylene trimerisation that uses this class of ligands. The most efficient $\mathrm{Cr}$-based catalytic system was based on $\mathrm{Cr}^{\mathrm{III}}-2$ ethylhexanoate and glyoxal bis(1,1,3,3-tetramethylbutylimine). However, these catalysts present a low selectivity in 1-hexene, which is formed together with other internal hexenes and, therefore, difficult to be extracted. Another approach to create catalytic systems, which can interchange trimerisation with polymerisation activity, starts from single trimerisation systems which are not able to selectively form 1-hexene and, by-products such as 1-butene, 1-octene, 1-decene and even heavier oligomers are also produced.

Recently, we reported on a novel Cr-based heterogeneous catalytic system. By coordinating a TAC ligand onto a coordinatively unsaturated $\mathrm{Cr}^{\mathrm{II}}$ site, a trimerisation site was assembled on a silica surface [25]. Its structure consists of a coordinated TACring at $\mathrm{Cr}$ centre and one chloride ligand, besides two links with the silica carrier $[25,26]$. In this paper, we present the catalytic activity of the assembled site as well as one way to interchange trimerisation activity with polymerisation activity by means of the reaction conditions. In this way, a dual trimerisationpolymerisation catalytic system is obtained and it represents a step further in designing a heterogeneous one-pot catalyst for the production of linear low density polyethylene. Moreover, a detailed characterisation of polymers produced under different reaction conditions is reported.

\section{Experimental}

\subsection{Catalyst preparation}

The study starts from an industrial-like $\mathrm{Cr} / \mathrm{SiO}_{2}$ Phillips catalyst with a loading of $1 \mathrm{wt} . \% \mathrm{Cr}$, which was subsequently reduced in $\mathrm{CO}$ in order to create $\mathrm{Cr}^{\mathrm{II}}$ polymerisation sites. The reduction treatment was carried out in a closed spectroscopic cell [27] wherein a flow of $30 \mathrm{ml} / \mathrm{h}$ pure $\mathrm{CO}$ was passed for $30 \mathrm{~min}$ through a catalyst bed with an average particle size of $0.2-0.4 \mathrm{~mm}$. The reduced $\mathrm{CrI} / \mathrm{SiO}_{2}$ catalyst was modified afterwards inside an inert atmosphere by putting it in contact for 10 min with a solution of a TAC (1,3,5-tribenzylhexahydro 1,3,5-triazine) compound (Aldrich, 99.9\%) dissolved in extradry dichloromethane. The amount of TAC was calculated to obtain a Cr:TAC ratio of 1:1 and the excess of solvent was evaporated at room temperature.

\subsection{Catalyst testing}

All catalytic tests were done in a slurry system using toluene as dispersing medium. Two sets of parameters were examined, one set close to industrial conditions (slurry system, low and high pressures and a temperature of $90^{\circ} \mathrm{C}$ ) and another one close to the homogeneous complex catalysis conditions (slurry system, low pressure and a temperature of $25^{\circ} \mathrm{C}$ ). The reaction time was $1 \mathrm{~h}$ for all experiments. The $\mathrm{CrCl}_{3}$-TAC homogeneous reference complex was tested under identical reaction conditions and using the same co-catalyst.

The experimental set-up for low-pressure experiments consists of a glass reactor equipped with a natural rubber cap and a side faucet that establish the connection with the bubbler. The ethylene is continuously flushed into the system via a stainless steel needle through the rubber septum. The exit of the gas from the bubbler is connected to a micro GC device that can accumulate sequentially gas chromatograms. The ethylene flow rate was maintained at $30 \mathrm{ml} / \mathrm{min}$. The bubbler is filled with $32-35 \mathrm{ml}$ toluene and the reactor is filled with $25 \mathrm{ml}$ toluene, both inside the glove box and using extra-dry and deoxygenated toluene. 
High-pressure catalytic tests were carried out in a pressurised 11 metallic reactor from Parr Instruments. A continuous feedstock of ethylene was introduced into the metal reactor to reach and equilibrate the reaction pressure.

In order to evaluate the catalytic properties, the catalytic materials were activated with $0.04 \mathrm{mmol}$ of $\mathrm{N}, \mathrm{N}$ dimethylanilinium tetra(pentafluoro-phenyl) borate (DMAB) and with 20 equiv. of triisobutyl-aluminium. Careful precautions have been taken in order to avoid deactivation of the catalyst. Therefore, extra-dry and deoxygenated toluene was used.

Reaction products were identified using the electron-impact GC-MS technique for products found in the liquid phase, while the routine analysis were performed on a Chromapack CP 9001 gas-chromatograph. Reaction products found in the gas phase were identified and analysed by a Varian CP 4900 micro-GC that permits a sample injection each $2 \mathrm{~min}$. A gaseous mixture of ethylene, 1-propene, 1-butene, 1-pentene and 1-hexene was used for the calibration of the micro-GC.

\subsection{Polymer characterisation}

The solid products, respectively, the polymer and the heavy oligomers, were analysed by XRD, DSC, GPC and ${ }^{13} \mathrm{C}$ and ${ }^{1} \mathrm{H}$ NMR techniques.

$\mathrm{X}$-ray diffraction (XRD) patterns of polymers were recorded in air at $25^{\circ} \mathrm{C}$, with a $2 \theta$ step size of $0.05^{\circ}$. An ENRAF Nonius PDS 120 diffractometer equipped with a focus graphite monochromdiffracted beam and with a proportional counter having electronic pulse-height discrimination was used. A divergence slit of $0.5^{\circ}$, a receiving slit of $0.2 \mathrm{~mm}$, an anti-scatterer slit of $0.5^{\circ}$ and a Co K $\alpha$ radiation $(30 \mathrm{~mA}, 30 \mathrm{kV}, \lambda=1.78897 \AA$ ) were employed during measurements. Lorentz functions were used to separate the contribution of amorphous and crystalline phases.

Differential scanning calorimetry (DSC) was used to perform the thermal analysis of the solid products on a Universal V4.1D calorimeter from TA Instruments at a heating rate of $10^{\circ} \mathrm{C} / \mathrm{min}$ under nitrogen atmosphere. Four milligrams of sample was firstly equilibrated at $20^{\circ} \mathrm{C}$ and then heated to $200^{\circ} \mathrm{C}$ to erase the thermal history of the sample. Then, the sample was cooled down at $20^{\circ} \mathrm{C}$ with $10^{\circ} \mathrm{C} / \mathrm{min}$ and only the second scan was reported in order to eliminate the differences between cycles. The peak temperature of the highest endotherm was chosen as $T_{\mathrm{m}}$.

Gel permeation chromatography (GPC) analysis was carried out on a Polymer Laboratories Ltd. Chromatograph at $135^{\circ} \mathrm{C}$ using 1,2,4-trichlorobenzene (TCB) as mobile phase. The molecular weight was referenced to a polyethylene standard with $M_{\mathrm{w}}=50,000 \mathrm{~g} / \mathrm{mol}$. The distribution curve graph was normalised by the factor 0.1004 .

Solid-state NMR spectra were recorded on a Brucker AV300 Instruments $\left(300 \mathrm{MHz}\right.$ for ${ }^{13} \mathrm{C}$ NMR and $500 \mathrm{MHz}$ for ${ }^{1} \mathrm{H}$ NMR) apparatus. Chemical shifts were referenced internally to the major backbone methylene carbon and hydrogen resonances of TCB (1,2,4-trichlorobenzene) and PDCB (para-dichlorobenzene), respectively. The solvents were used to provide the internal lock signal. Seventy-seven milligrams of solid product was dissolved at $135^{\circ} \mathrm{C}$ in $1.5 \mathrm{ml}$ TCB or PDCB and $0.5 \mathrm{C}_{6} \mathrm{D}_{6}$ was added. A typical measurement was carried out for $2 \mathrm{~h}$ in ${ }^{1} \mathrm{H}$ NMR mode and for $60 \mathrm{~h}$ in ${ }^{13} \mathrm{C}$ NMR mode.

\section{Results and discussion}

\subsection{Trimerisation versus polymerisation activity}

After heterogenisation, the trimerisation centre presents a boost in its catalytic activity as the catalytic tests performed at low pressures show. Fig. 1 presents the catalytic activity of the assembled $\mathrm{TAC}-\mathrm{CrCl} / \mathrm{SiO}_{2}$ catalyst at low pressures in comparison with the $\mathrm{TAC}-\mathrm{CrCl}_{3}$ homogeneous reference. It can be noticed that the catalyst has a bi-functional nature and, from a single ethylene feedstock, both expected products are formed, free 1-hexene and a solid product $[28,29]$. Moreover, up to three times more 1-hexene is produced in comparison with its homogeneous trimerisation reference compound and the polymerisation activity is up to two times higher. No other light olefins such as $\mathrm{C}_{4}, \mathrm{C}_{8}, \mathrm{C}_{10}$ or heavier olefins, were detected in the liquid phase. Therefore, the selectivity in free 1-hexene in the liquid phase was estimated as being higher than $90 \%$. Under identical reaction conditions, the homogeneous reference compound presents a lower selectivity in free 1-hexene; i.e., $57 \%$. This difference in ethylene trimerisation activity is also evident from Table 2 when comparing the turnover frequencies (TOF) of both catalyst systems. Approximately three times more $\mathrm{Cr}$ sites are necessary in case of the homogeneous reference compound to obtain almost the same amount of 1-hexene. At a reaction temperature of $90^{\circ} \mathrm{C}$, the selectivity of the heterogeneous trimerisation system decays significantly, most likely, due to the incorporation of 1-hexene into the polymer.

For the high-pressure catalytic tests, besides 1-hexene and the solid product, traces of heavy oligomers of ethylene can be detected in the liquid phase as well. This decrease in 1-hexene selectivity is determined by the significant enhancement of the polymerisation activity, more favoured at higher pressures than trimerisation. Now, the polymerisation activity becomes dominant and, consequently, considerable amounts of solid products are formed as can be seen in Fig. 2.

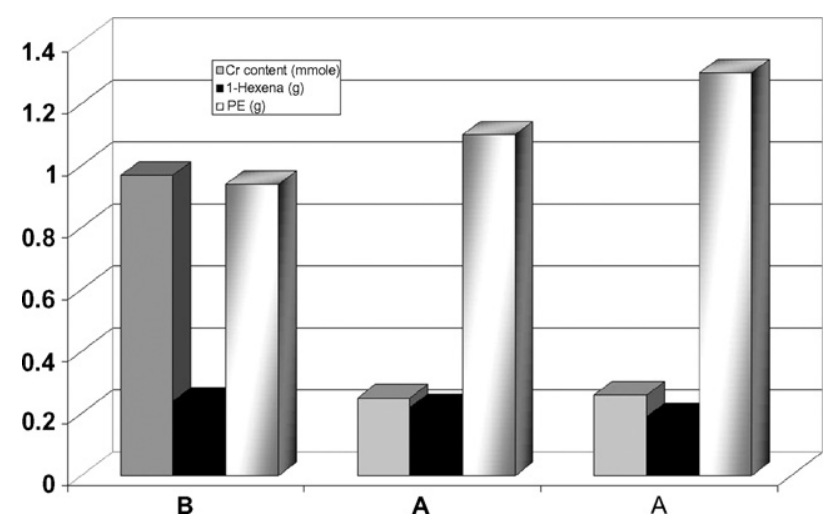

Fig. 1. Catalytic activity of the TAC-CrCl/SiO 2 catalyst (A) and its homogeneous reference $\mathrm{TAC}-\mathrm{CrCl}_{3}$ compound (B) at 1 bar and different reaction temperatures. 
Table 2

Trimerisation and polymerisation activities of $\mathrm{TAC}-\mathrm{CrCl} / \mathrm{SiO}_{2}$ and $\mathrm{TAC}-\mathrm{CrCl}_{3}$ catalysts under different reaction conditions

\begin{tabular}{|c|c|c|c|c|c|}
\hline Catalytic system & Cr:TAC ratio & Reaction variable & Other reaction conditions & 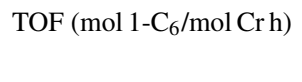 & $\begin{array}{l}\text { Polymerisation activity } \\
\left(\mathrm{g}_{\mathrm{PE}} / \mathrm{mol} \mathrm{Cr} \mathrm{h}\right)\end{array}$ \\
\hline \multirow{3}{*}{$\mathrm{TAC}-\mathrm{CrCl} / \mathrm{SiO}_{2}$} & 1 & 1 bar & \multirow{3}{*}{$25^{\circ} \mathrm{C}, 100 \mathrm{ml}$ toluene, $2 \mathrm{~g}$ catalyst } & 0.01 & 2.30 \\
\hline & 1 & 10 bar & & 0.11 & 2.47 \\
\hline & 1 & 30 bar & & 1.01 & 25.16 \\
\hline $\mathrm{TAC}-\mathrm{CrCl} / \mathrm{SiO}_{2}$ & 1 & $25^{\circ} \mathrm{C}$ & $1 \mathrm{bar}, 30 \mathrm{ml}$ toluene, $2 \mathrm{~g}$ catalyst & 9.6 & 4.40 \\
\hline
\end{tabular}

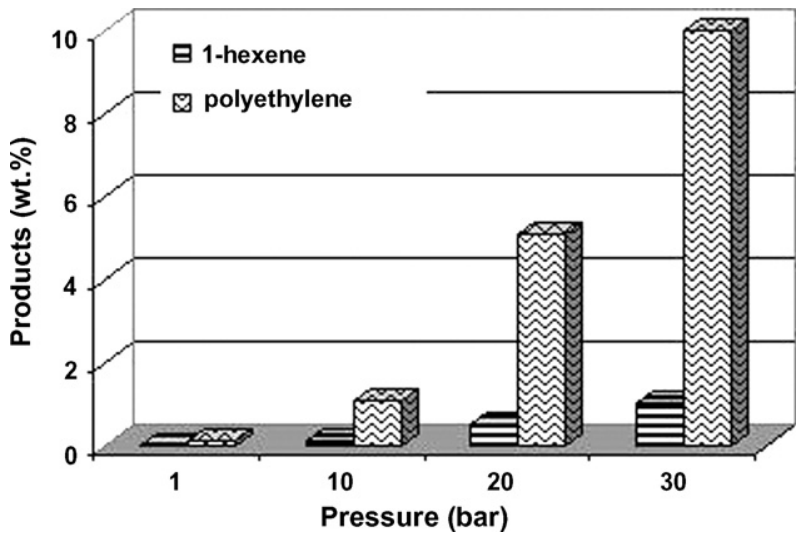

Fig. 2. Catalytic activity of the $\mathrm{TAC}-\mathrm{CrCl} / \mathrm{SiO}_{2}$ catalyst at high ethylene pressures and $25^{\circ} \mathrm{C}$.

Despite of the enhanced polymerisation activity at high pressures, the production of 1-hexene is also favoured by increasing pressures and increases almost linearly with increasing pressure as Fig. 3 shows. The production of the polymer follows a similar trend. It might be possible that the incorporation degree of 1-hexene into the growing polymer chain will increase also with increasing the ethylene pressure at the expense of the free 1hexene. Therefore, the structure of the formed polymers should be investigated.

It was found that the homogeneous trimerisation catalyst, $\mathrm{CrCl}_{3}-\mathrm{TAC}$ starts immediately to produce 1-hexene, while the $\mathrm{TAC}-\mathrm{CrCl} / \mathrm{SiO}_{2}$ catalyst needs an induction period. This induc-

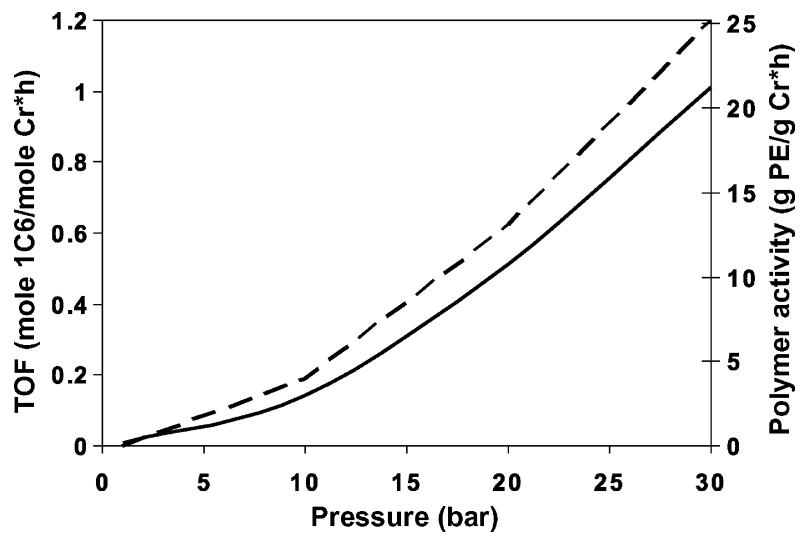

Fig. 3. Influence of the ethylene pressure on 1-hexene formation (solid line) and polymer formation (broken line).

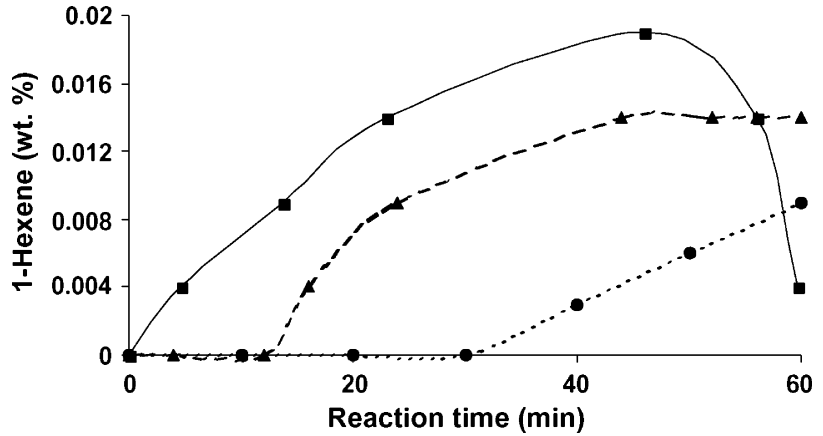

Fig. 4. Production of 1-hexene in the gas phase as a function of reaction time at $1 \mathrm{bar}$ - and solid line for $\mathrm{CrCl}_{3}-\mathrm{TAC}$ reference, $\boldsymbol{\Lambda}$ and broken line corresponding to $\mathrm{TAC}-\mathrm{CrCl} / \mathrm{SiO}_{2}$ and - and dotted line corresponding to $\mathrm{TAC}-\mathrm{CrCl} / \mathrm{SiO}_{2}$ at 30 bar.

tion period depends on the reaction pressure, 1-hexene being later formed at pressures higher than 1 bar (Figs. 4 and 5).

The homogeneous and heterogeneous $\mathrm{Cr}$ catalysts also possess a different deactivation pattern. The homogeneous $\mathrm{CrCl}_{3}-\mathrm{TAC}$ trimerisation catalyst starts to deactivate after a short time $(30 \mathrm{~min})$ due to the trimerisation of 1-hexene to a $\mathrm{C}_{18}$ fraction. In contrast, $\mathrm{TAC}-\mathrm{CrCl} / \mathrm{SiO}_{2}$ presents an increasing trimerisation activity for very long time, especially at high pressures compensating its delay from the beginning of the reaction. At 1 bar, the decay in trimerisation activity should appear later than $60 \mathrm{~min}$, while, at $30 \mathrm{bar}$, even after $240 \mathrm{~min}$ reaction time, the drop in the trimerisation activity does not appear. In fact, the formation of 1-hexene exhibits a relatively linear tendency (Fig. 5).

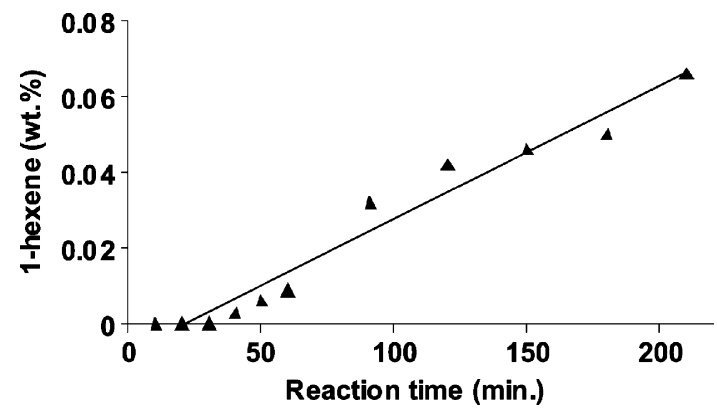

Fig. 5. Production of 1-hexene at $30 \mathrm{bar}$ in the liquid phase as a function of the reaction time. 
Table 3

${ }^{13} \mathrm{C}$ NMR chemical shifts of the solid product obtained with a $\mathrm{TAC}-\mathrm{CrCl} / \mathrm{SiO}_{2}$ catalyst at 1 bar and $25^{\circ} \mathrm{C}$

\begin{tabular}{ll}
\hline Carbon groups & Chemical shift $(\mathrm{ppm})$ \\
\hline$=\mathrm{CH}-$ & 139.05 \\
$=\mathrm{CH}_{2}$ & 114.15 \\
$\mathrm{CH}_{2}(\mathrm{iPr})$ & 39.50 \\
$\mathrm{CH}$ & $38.14-32.15$ \\
$\mathrm{CH}_{2}(\alpha)$ & $34.53-32.15$ \\
$\mathrm{CH}_{2}(\gamma)$ & $32.15-23.34$ \\
$\mathrm{CH}_{2}$ & 29.95 \\
$\mathrm{CH}_{2}(\beta)$ & $29.50-27.26$ \\
$\mathrm{CH}_{(}(\mathrm{iPr})$ & 28.30 \\
$\mathrm{CH}_{3}(\mathrm{iPr})$ & 22.70 \\
$\mathrm{CH}_{3}\left(\delta^{\prime}\right)$ & 14.04 \\
\hline
\end{tabular}

\subsection{Solid products characterization}

\subsubsection{Solid product obtained at 1 bar ethylene pressure}

Using ${ }^{13} \mathrm{C}$ NMR spectroscopy, the identification of the solid products formed during ethylene trimerisation/polymerisation was performed. The assignment of the different NMR signals observed is summarised in Table 3. Butyl side-chains are put in evidence by the chemical shifts $14.04 \mathrm{ppm}\left(\mathrm{CH}_{3}\right), 34.5-32.15$ $\left(\mathrm{CH}_{2}\right)$ and $32.15 \mathrm{ppm}(\mathrm{CH})$, isobutyl branches are evidenced by the presence of the chemical shifts at $22.7 \mathrm{ppm}$ and $22.9 \mathrm{ppm}$ $\left(\mathrm{CH}_{3}\right), 28.3 \mathrm{ppm}(\mathrm{CH})$ and $39.5 \mathrm{ppm}\left(\mathrm{CH}_{2}\right)$ and isopropyl corresponds to chemical shifts at $22.7 \mathrm{ppm}\left(\mathrm{CH}_{3}\right)$ and $28.3 \mathrm{ppm}(\mathrm{CH})$ $[20,30]$. Some peaks, respectively, $33.4 \mathrm{ppm}\left(\mathrm{CH}_{2}\right), 27.6 \mathrm{ppm}$ $\left(\mathrm{CH}_{2}\right), 26.7 \mathrm{ppm}\left(\mathrm{CH}_{2}\right), 20.4 \mathrm{ppm}\left(\mathrm{CH}_{2}\right)$ and $18.9 \mathrm{ppm}\left(\mathrm{CH}_{3}\right)$ from the ${ }^{13} \mathrm{C}$ NMR spectrum could not be assigned to the short side chain usually found in the structure of a classical polyethylene. However, this solid product contains short branches grafted on a $\left(\mathrm{CH}_{2}\right)_{n}$ linear structure as indicated by the NMR peak at $27.3 \mathrm{ppm}$ assigned to butyl chains [20,30,31], its spectrum does not correspond to a classical polyethylene structure. Long chain branches, respectively branches longer than hexyl chains, are related to the chemical shifts at 32.16, 29.6 and $38.24 \mathrm{ppm}$ [30,32-34]. ${ }^{1} \mathrm{H}$ NMR spectrum is also different from the spectrum of a classical polyethylene. The linear $\mathrm{CH}_{2}$ backbone is evidenced by the signal at $1.3 \mathrm{ppm}$, while the doublet at $0.86-0.87 \mathrm{ppm}$ indicates the presence of the isopropyl group. Isopropyl and isobutyl terminations as well as traces of the oxygenated compounds observed in ${ }^{1} \mathrm{H}$ NMR spectrum appear as a consequence of the use of the co-catalyst $\mathrm{Al}(\mathrm{iBu})_{3}$.

Quantitative results of this solid product are summarised in Table 4. They indicate a high number of methyl groups due to

Table 4

Quantitative results for the solid product obtained with a $\mathrm{TAC}-\mathrm{CrCl} / \mathrm{SiO}_{2}$ catalyst at 1 bar and $25{ }^{\circ} \mathrm{C}$ according to ${ }^{13} \mathrm{C}$ and ${ }^{1} \mathrm{H}$ NMR analysis

\begin{tabular}{lc}
\hline Termination ends & Branches per 1000 C \\
\hline Methyl ends & 140 \\
Vinyl ends & 5 \\
Vinylidene ends & 2 \\
Short chain branches & 25 \\
$i$-Propyl ends & 25 \\
\hline
\end{tabular}

the presence of side-chains. A part of these branches appears as a result of the incorporation of 1-hexene (butyl chains).

No defined melting temperature could be obtained for this sample. Indeed, DSC measurements indicate a continuous melting behaviour, specific for amorphous materials. This finding is complemented by XRD measurements, which show also a total lack of crystallinity. Most likely, this is due to the entanglements of the molecules, which depress crystallisation and leads to low crystallinity [35]. Summarising, the solid product obtained at 1 bar is completely amorphous.

The average molecular weight of this solid product is low as indicated by GPC measurements. The obtained value of $324 \mathrm{amu}$ indicates that the solid product is more a heavy oligomer of ethylene than a polymer. The solid product obtained at 1 bar presents a remarkable narrow distribution of the average molecular weight $\left(M_{\mathrm{W}}\right)$ that indicates equal-length polymeric chains [25]. This feature of the solid product reflects the single-site behaviour of the TAC- $\mathrm{CrCl} / \mathrm{SiO}_{2}$ catalyst.

\subsubsection{Solid products obtained at higher ethylene pressures}

By comparing the ${ }^{1} \mathrm{H}$ NMR spectra of the solid products obtained at high pressures with those obtained at 1 bar, differences are noticed. Methyl groups characterised by the chemical shifts at $0.38,0.86$ and $1.22 \mathrm{ppm}$ and methylene groups at $1.35 \mathrm{ppm}$ and at 3.27-3.31 ppm were identified. The NMR spectra of these solid products present a close resemblance with that of high-density polyethylene. Short chains, especially methyl, are present but not in great amounts.

In general, a polymer has a mixed amorphous-crystalline macromolecular structure. The presence of crystalline structures influences significantly properties such as hardness, stiffness, melting point, modulus and tensile. The amount of crystalline regions in the polymer is given by the crystallinity degree, which can be determined by several methods such as DSC and XRD.

With DSC, the melting behaviour of the polymer is studied and features such as glass transition, crystallisation temperature $\left(T_{\mathrm{c}}\right)$ or melting temperature $\left(T_{\mathrm{m}}\right)$ can be determined. Sample crystallinity $\left(X_{\mathrm{c}}\right)$ is defined as

$X_{\mathrm{c}}=\frac{\Delta H_{\mathrm{f}}}{\Delta H_{\mathrm{f}}^{\circ}}$

where $\Delta H_{\mathrm{f}}$ and $\Delta H_{\mathrm{f}}^{\circ}$ are the melting enthalpy of the polymer and the melting enthalpy of a polyethylene reference with $100 \%$ crystallinity. $\Delta H_{\mathrm{f}}$ is acquired by integration of the area under the DSC heating curve and $\Delta H_{\mathrm{f}}^{\circ}=273 \mathrm{~J} / \mathrm{g}$ [36].

As can be seen in Table 5, the solid products obtained at high ethylene pressures can be considered as high density polyethylene since they possess melting and onset temperatures $\left(T_{\mathrm{m}}\right.$ and $T_{\mathrm{o}}$ ) very close to those of a standard HDPE. Also, their crystallinity degrees, comparable with those of HDPEs, are indicative for highly crystalline polymers.

$\mathrm{X}$-ray diffraction is also used to measure the extent of crystallinity present in the polymers [37]. It is important to know that, the crystallinity values obtained with XRD differ slightly from values measured with DSC because the last method determines certain conformational changes during the measurement induced by the sample heating $[37,38]$. In Table 6 , 
Table 5

DSC results for the solid products obtained with the $\mathrm{TAC}-\mathrm{CrCl} / \mathrm{SiO}_{2}$ catalyst at $25^{\circ} \mathrm{C}$ for different ethylene pressures

\begin{tabular}{|c|c|c|c|c|c|c|}
\hline $\begin{array}{l}\text { Solids obtained at } \\
\text { different pressures }\end{array}$ & Weight (mg) & $T_{\mathrm{c}}\left({ }^{\circ} \mathrm{C}\right)$ & $T_{\mathrm{o}}\left({ }^{\circ} \mathrm{C}\right)$ & $T_{\mathrm{m}}\left({ }^{\circ} \mathrm{C}\right)$ & $\Delta H(\mathrm{~J} / \mathrm{g})$ & $X_{\mathrm{c}}(\%)$ \\
\hline 10 bar $^{\mathrm{a}}$ & 4.20 & 118 & 131.3 & 134.9 & 181.2 & 66.37 \\
\hline 20 bar $^{\mathrm{a}}$ & 4.49 & 115 & 130.9 & 134.0 & 169.4 & 62.50 \\
\hline 30 bar $^{b}$ & 3.04 & 115 & 124.8 & 132.9 & 199.0 & 72.89 \\
\hline $\mathrm{LDPE}^{\mathrm{c}}$ & 10.67 & - & - & 114.6 & - & - \\
\hline LLDPE $^{\mathrm{c}}$ & 8.27 & - & - & 126.6 & - & - \\
\hline
\end{tabular}

\footnotetext{
a Polymers obtained in $100 \mathrm{ml}$ toluene slurry phase for $60 \mathrm{~min}$.

b Polymer obtained in $300 \mathrm{ml}$ toluene slurry phase for $3.5 \mathrm{~h}$.

c Reference polyethylene samples.
}

Table 6

Crystallinity degrees $\left(X_{\mathrm{c}}\right)$ of the polymers obtained with a $\mathrm{TAC}-\mathrm{CrCl} / \mathrm{SiO}_{2}$ catalyst at $25^{\circ} \mathrm{C}$ for different ethylene pressures as evaluated by DSC and XRD

\begin{tabular}{lll}
\hline $\begin{array}{l}\text { Solids obtained at different } \\
\text { pressures (bar) }\end{array}$ & $X_{\mathrm{c}}(\%)$ (DSC) & $X_{\mathrm{c}}(\%)$ (XRD) \\
\hline 10 & 66.37 & 50.01 \\
20 & 62.50 & 63.71 \\
30 & 64.10 & 69.29 \\
\hline
\end{tabular}

the crystallinity degree of the polymers analysed with DSC and $\mathrm{XRD}$ is compared.

As an example, Fig. 6 shows the main peaks of the XRD pattern of the polymer obtained at 30 bar. The peaks (110) and $(200)$ at $21.5^{\circ}$ and $23.8^{\circ}$, respectively correspond to the orthorhombic reflections of polyethylene, while the peak (0 01$)$ at $19.4^{\circ}$ corresponds to a monoclinic phase of polyethylene [37,38]. The last peak appears infrequently in linear polyethylenes [37]. In fact, the monoclinic phase seldom exceeds $10 \%$ of the total crystalline content of a polymer. The presence of this phase confers remarkable properties to polymers made at high pressures.

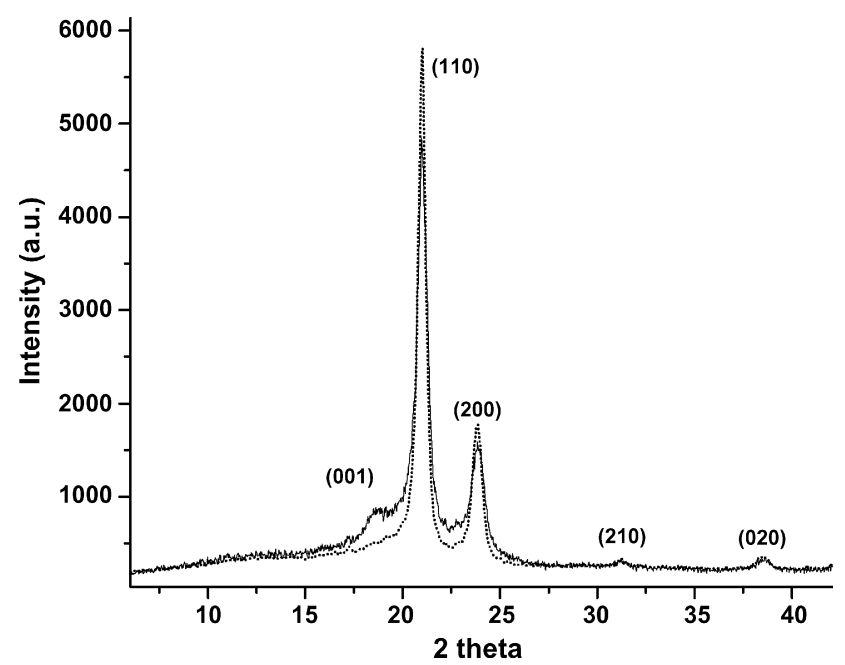

Fig. 6. XRD pattern of the polymer obtained with a $\mathrm{TAC}-\mathrm{CrCl} / \mathrm{SiO}_{2}$ catalyst at 30 bar and $25^{\circ} \mathrm{C}$ (solid line) in comparison with an UHMWPE standard (dotted line).
The unexpected presence of this phase in our polymer samples obtained at high pressure demonstrates that the polymers present highly ordered crystals in a non-entangled chains conformation probably due to an optimal combination of crystallisation conditions, respectively, $25^{\circ} \mathrm{C}$ reaction temperature and high pressures. For comparison reasons, in Fig. 6, a diffraction pattern of a UHMWPE reference polymer with high crystallinity degree is shown where the monoclinic phase is missing.

Data of thermal analysis of the polymers obtained at high pressures converge with the XRD findings: high melting temperatures $\left(132-135^{\circ} \mathrm{C}\right)$, high heats of melting $(169-199 \mathrm{~J} / \mathrm{g})$ and high melt indexes $\left(0.95 \mathrm{~g} / \mathrm{cm}^{3}\right)$. Polymers poor-solubility in NMR and GPC solvents can be considered as an additional evidence for the compact structures and relatively high molecular weights of these solid products. Similarly with the solid product obtained at 1 bar, these products should present a narrow distribution of the average molecular weights in spite of their very high average molecular weight.

In Table 7, the most important features of the solid products acquired from the above mentioned characterisation methods are summarised. Noticeable differences can be seen between the solid products obtained at different ethylene pressures. Based on its low molecular weight, its highly branched structure and its amorphous character, we consider that the solid made at 1 bar does not correspond to a polymer and, in fact, is a heavy oligomer of ethylene. In contrast, at higher ethylene pressures, real polyethylene-type polymers with a high molecular weight and crystallinity are produced. These solids can be considered as

Table 7

Comparison of the solid products obtained with a $\mathrm{TAC}-\mathrm{CrCl} / \mathrm{SiO}_{2}$ catalyst at $25^{\circ} \mathrm{C}$ and at different ethylene pressures

\begin{tabular}{lll}
\hline Polymer characteristics & $\begin{array}{l}\text { Solid product } \\
\text { obtained at } 1 \mathrm{bar}\end{array}$ & $\begin{array}{l}\text { Solid products } \\
\text { obtained at }>1 \mathrm{bar}\end{array}$ \\
\hline Skeletal structure & Highly branched & $\begin{array}{l}\text { Almost no } \\
\text { branches } \\
\text { Very high }\end{array}$ \\
Average molecular weight & $324 \mathrm{amu}$ & - \\
Polydispersity index & 1.87 & $138-140{ }^{\circ} \mathrm{C}$ \\
Melting temperature & Undefined & $0.9546 \mathrm{~g} / \mathrm{cm}^{3}$ \\
Melt index & - & $62-72 \%$ \\
Crystallinity & Amorphous & Polymer \\
Nature of the solid product & Oligomer &
\end{tabular}


high-density polyethylene-type polymers enriched with a monoclinic phase.

\section{Conclusions}

Based on the catalytic results presented in this work, it can be concluded that a novel heterogeneous Cr-based bi-functional catalyst was developed, which shows, depending on the reaction conditions, either a predominant ethylene trimerisation or polymerisation behaviour. At low pressures, the $\mathrm{TAC}-\mathrm{CrCl} / \mathrm{SiO}_{2}$ catalyst is a very active ethylene trimerisation catalyst, which is further characterised by its induction period and long deactivation time. At high pressures, the trimerisation activity is interchanged with the polymerisation activity. The induction period is slightly extended, while the deactivation time is increased. Ethylene pressure influences also the nature of the solid products. A highly branched heavy oligomer of ethylene with an amorphous character, a low average molecular weight, but with a very narrow molecular weight distribution is obtained at 1 bar. NMR demonstrated that part of the branches are butyl side-chains, originating from 1-hexene, partially incorporated into the growing oligomer. In contrast, at higher pressures, polymers are produced. They are highly crystalline as indicated by the melting temperature, melt enthalpy, melt index and crystallinity degree. Furthermore, side branches are infrequently present and in low amount. These characteristics point toward the formation of high-density polyethylene. Summarising, at low reaction pressures, the $\mathrm{TAC}-\mathrm{CrCl} / \mathrm{SiO}_{2}$ catalyst makes redundant the use of a second ethylene feedstock and the use of an expensive Pd-based catalyst in order to obtain 1-hexene as copolymerisation agent. At high reaction pressures, HDPE-type polymers enriched with a monoclinic phase can be obtained using this novel catalytic system.

\section{Acknowledgments}

The authors wish to kindly thank Dr. T.A. Nijhuis for his suggestions regarding catalytic tests and their interpretation. Dr. H. Talsma is gratefully acknowledged for performing DSC measurements. Furthermore, Dr. R. Dabirian is thanked for the NMR measurements of the polymers made. Total Petrochemicals Research, Feluy, Belgium, has sponsored part of this research.

\section{References}

[1] J.R. Briggs, J. Chem., Soc., Chem. Commun. (1989) 674-675.

[2] A. Carter, S.A. Cohen, N.A. Cooley, A. Muphy, J. Scutt, D.F. Wass, Chem. Commun. (2002) 858-859.
[3] R. Emrich, O. Heinemann, P.W. Jolly, C. Kruger, G.P.J. Verhovnik, Organometallics 16 (1997) 1511-1513.

[4] T. Monoi, Y. Sasaki, J. Mol. Catal. A: Chem. 187 (2002) 135-141.

[5] F. Alobaidi, Z. Ye, S. Zhu, J. Polym. Sci. A: Polym. Chem. 42 (2004) $4327-4336$

[6] R.F. de Souza, O.L.J. Casagrande, Macromol. Rapid Commun. 22 (2001) 1293-1301.

[7] Z.J.A. Komon, G.C. Bazan, Macromol. Rapid Commun. 22 (2001) 467-478.

[8] R. Quijada, R. Rojas, G.C. Bazan, Z.J.A. Komon, R.F. Mauler, G.B. Galland, Macromolecules 34 (2001) 2411-2417.

[9] W.M. Woodard, W.M. Ewert, H.D. Hensley, M.E. Lashier, B.E. Kreischer, WO 99/19280, 1997.

[10] P.J.W. Deckers, B. Hessen, J.H. Teuben, Angew. Chem. Int. Ed. 40 (2001) 2516-2519.

[11] B. Hessen, J. Mol. Catal. A: Chem. 231 (2004) 129-135.

[12] G.J.P. Britovsek, V.C. Gibson, D.F. Wass, Angew. Chem. Int. Ed. 38 (1999) $428-447$.

[13] K.H. Theopold, Eur. J. Inorg. Chem. (1998) 15-24.

[14] J.J.C. Grove, H.A. Mahomed, L. Griesel, WO 03/004158, 2002.

[15] H. Mahomed, A. Bollmann, J.T. Dixon, V. Gokul, L. Griesel, C. Grove, F. Hess, H. Maumela, L. Pepler, Appl. Catal. A: Gen. 255 (2003) 355359.

[16] F.J. Wu, EP 0537609, 1992.

[17] P. Wasserscheid, S. Grimm, R.D. Kohn, M. Haufe, Adv. Synth. Catal. 343 (2001) 814-818

[18] S. Ittel, L.K. Johnson, M. Brookhart, Chem. Rev. 100 (2000) 11691204.

[19] F. Alobaidi, Z. Ye, S. Zhu, Macromol. Chem. Phys. 204 (2003) 16531659.

[20] G.B. Galland, R.F. de Souza, R.F. Mauler, F.F. Nunes, Macromolecules 32 (1999) $1620-1625$.

[21] Z. Guan, J. Polym. Sci. A: Polym. Chem. 41 (2003) 3680-3692.

[22] L.K. Johnson, C.M. Killian, M. Brookhart, J. Am. Chem. Soc. 117 (1995) 6414-6415.

[23] N. Suzuki, J. Yu, Y. Masubuchi, A. Horiuchi, Y. Wakatsuki, J. Polym. Sci. A: Polym. Chem. 41 (2003) 293-302.

[24] Z. Ye, H. Alsyouri, S. Zhu, Y.S. Lin, Polymer 44 (2003) 969-980.

[25] C.N. Nenu, B.M. Weckhuysen, Chem. Commun. (2005) 1865-1867.

[26] C.N. Nenu, F.M.F. de Groot, D.C. Koningsberger, B.M. Weckhuysen, Chem. Eur. J. 12 (2006) 4756-4763.

[27] B.M. Weckhuysen, R.A. Schoonheydt, Catal. Today 51 (1999) 215-221.

[28] P. Bodart, C.N. Nenu, B.M. Weckhuysen, WO 2005/082815 A1, 2005.

[29] C.N. Nenu, P. Bodart, B.M. Weckhuysen, EP 050565, 2005.

[30] T. Usami, S. Takayama, Macromolecules 17 (1984) 1756-1761.

[31] M. De Pooter, P.B. Smith, K.K. Dohrer, K.F. Bennett, M.D. Meadows, C.G. Smith, H.P. Schouwenaars, R.A. Geerards, J. Appl. Polym. Sci. 42 (1991) 399-408.

[32] D.C. Bugada, A. Rudin, Eur. Polym. J. 23 (1987) 809-818.

[33] E.W. Hansen, R. Blom, O.M. Bade, Polymer 37 (1997) 4295-4304.

[34] E.W. Hansen, K. Redford, H. Oysaed, Polymer 37 (1996) 19-24.

[35] D.C. Bassett, Principles of Polymer Morphology, Cambridge University Press, London, 1981.

[36] Y.M. Dong, The Practical Analysis Technology of Polymer Materials, Petrochemical Industry Press, Beijing, 1979.

[37] K.E. Russel, B.K. Hunter, R.D. Heyding, Polymer 38 (1997) 14091414.

[38] Y.L. Joo, O.H. Han, H.K. Lee, J.K. Song, Polymer 41 (2000) 1355-1368. 